\title{
Unexpected dilatation of the common bile duct after methyl tertiary butyl ether (MTBE) in rabbits. Possible implications to findings in man
}

\author{
R TRITAPEPE, C POZZI, P CASPANI, AND C DI PADOVA \\ From the Chair of Surgical Pathology, University of Milan School of Medicine, Milan, Italy
}

SUMMARY Methyl tertiary butyl ether (MTBE) rapidly dissolves cholesterol gall stones in vitro and in vivo. To further characterise tolerability and safety of this aliphatic ether, either MTBE (1 ml/kg body wt daily for two days) or an equal amount of saline was infused into the common bile duct (CBD) of eight cholecystectomised rabbits. Transient vomiting, dyspnoea and somnolence developed during MTBE instillation. Post-treatment values of serum transaminases and alkaline phosphatase were significantly higher in MTBE than in saline treated animals. Cholangiography one week after the last intraductal infusion showed a five-fold increase of CBD size in MTBE $v$ control rabbits. At autopsy histological signs of chemical cholangitis and mild duodenitis were noted in MTBE treated animals. Prompted by these findings, we performed a cholangiography in two patients who had received intraductal MTBE (about $0.2 \mathrm{ml} / \mathrm{kg}$ body wt daily for one or two days) one year before: an abnormal dilatation of the CBD was present, which might represent a specific, hitherto undescribed permanent sequela of MTBE administration.

Methyl tertiary butyl ether (MTBE) is a foul smelling volatile, inflammable aliphatic ether used as an octane enhancer in lead free petrol. ${ }^{1}$ Methyl tertiary butyl ether has a cholesterol solubilising capacity of $14 \mathrm{~g} / \mathrm{dl}$ and rapidly dissolves cholesterol gall stones in vitro. ${ }^{2}$ By direct instillation, MTBE required for to 16 hours to dissolve gall stones surgically implanted in canine gall bladder.' Dogs tolerated MTBE infusions into the gall bladder with minor clinical and biochemical side effects. On light microscopy, however, inflammatory changes of the gall bladder and occasional signs of duodenitis were detected.

Clinical experience with MTBE infused into the gall bladder for the treatment of cholesterol stones has shown three main side effects - that is, sedation, burning upper abdominal pain at the start of each infusion, and possible maceration and disruption of catheters made of percuflex material. ${ }^{34}$ Intraductal

Address for correspondence: Raffaele Tritapepe, MD, Chair of Surgical Pathology, University of Milan, School of Medicine, Via S Calimero, 7, I-20122 Milan, Italy.

Accepted for publication 28 July 1988 . administration of low dose MTBE produced minor signs of systemic toxicity in small series of patients. ${ }^{5-7}$

To further assess the immediate and delayed effects of MTBE administration, we planned to inject this compound directly into the common bile duct (CBD) of cholecystectomised rabbits. In addition, we thought it of interest to extend our evaluation to two patients previously treated with intraductal MTBE for residual CBD stones.

\section{Methods}

ANIMAL EXPERIMENTS

Eight female New Zealand rabbits (Charles River, Italy), weighing about $3 \mathrm{~kg}$, fasted overnight, were operated under anaesthesia induced with $25 \mathrm{mg} / \mathrm{kg}$ body wt of pentobarbital sodium. ${ }^{8}$ The gall bladder was removed and the cystic duct was cannulated with a polyethylene tubing (PP 10, Portex, England) whose external arm was placed subcutaneously. Experiments were delayed three days after surgery. At this point, the rabbits were reoperated under local anaesthesia: the skin was incised and the external 
arm of the catheter was identified and exteriorised. The animals were randomly allocated to two groups: four rabbits were given intraductal MTBE (Fluka AG, Buchs, Switzerland; $1 \mathrm{ml} / \mathrm{kg}$ body wt daily for two days), the others received equal amounts of intraductal saline. Both solutions were infused continuously through the indwelling biliary drainage at a rate of $1 \mathrm{ml} / \mathrm{h}$ by a precision infusion pump (Minipuls II, Gilson, France). Owing to the small size of the infusion catheter no infusion/aspiration cycle was carried out. Before and after treatment venous blood was collected and assayed for liver function tests, and bile cultures for aerobic and anaerobic bacteria were carried out. ${ }^{9}$ Cholangiography was performed by injection of the contrast medium (Angiografin, Schering AG, Berlin, FRG, $0.5 \mathrm{ml}$ diluted with saline, 1:1, v:v) through the indwelling catheter at baseline and one week after the last intraductal infusion of MTBE or saline. Cholangiographic procedures were similar to those reported elsewhere. ${ }^{10}$ Briefly, a Diagnost 100 apparatus (Iontomat Focus 0.60 , Philips, Nederland) was used. The focus to film distance was $100 \mathrm{~cm}$ and the exposure time was kept low to inhibit blurring on the films caused by the breathing. The animals were examined in the prone position. The volume of the CBD was calculated from radiographs by a modification of a previously validated technique ${ }^{11}$ assuming that the $C B D$ volume is equal to the sum of a series of truncated cones. In particular, we utilised the formula:

$$
\mathrm{V}=\sum_{\mathrm{i}=1}^{\mathrm{n}} \frac{\pi \mathrm{h}_{\mathrm{i}}}{3}\left(\mathrm{R}_{\mathrm{i}}^{2}+\mathrm{R}_{\mathrm{i}} \mathrm{r}_{\mathrm{i}}+\mathrm{r}_{\mathrm{i}}^{2}\right)
$$

where $h$ is equal to the maximum longitudinal axis and $\mathrm{R}, \mathrm{r}$ are the maximal and minimal radius. ${ }^{12}$ At autopsy specimens of the CBD, the liver and the duodenum were fixed with $10 \%$ formalin and then stained with haematoxylin and eosin for light microscopy evaluation.
HUMAN EXPERIMENTS

A 68 year old male patient and a 75 year old female patient from a previously published series ${ }^{4}$ were contacted one year after intraductal MTBE administration for retained CBD stones. In the first patient MTBE (11 ml over six hours equivalent to $0.2 \mathrm{ml} / \mathrm{kg}$ body wt) was instilled into the CBD through a Teflon intracatheter (5.7F, Olstyke, Denmark) introduced into the T-tube (15 F). At 30 minute intervals, $1 \mathrm{ml}$ MTBE was infused after aspiration of bile and residual MTBE. Gentle aspiration and reinfusion were continuously undertaken to generate stirring. The total amount of MTBE reaspirated during the entire procedure was $4 \mathrm{ml}$. In the second patient MTBE was infused on two consecutive days. Every 30 minutes, $0.7 \mathrm{ml}$ MTBE was instilled into the CBD for a total of about $11 \mathrm{ml} /$ day for two days (total of 22 $\mathrm{ml}$ equivalent to $0.32 \mathrm{ml} / \mathrm{kg}$ body $\mathrm{wt}$ ). By reaspiration, $8 \mathrm{ml}$ MTBE was retrieved. In both cases, no attempt was made to retain the MTBE infused into the CBD by a distal balloon. The two subjects volunteered to participate in this study by undergoing a complete reassessment of hepatic and pancreatic function tests and an intravenous cholangiography. The volume of the common bile duct was calculated by radiographs as previously described and was compared with the pretreatment values as well as with the values obtained in control subjects. Table 1 lists the demographic and clinical characteristics of all the patients. As MTBE treated subjects underwent a subsequent course of intraductal monooctanoin, both patients treated with intraductal saline or monooctanoin served as controls. The modalities of the saline washouts after intravenous ceruletide and of monooctanoin administration were similar to those previously described. ${ }^{1314}$ Briefly, after an overnight fast, the patients received iv ceruletide (Takus, Farmitalia, Milan, Italy) at the dose of $2 \mathrm{ng} / \mathrm{kg}$ body $\mathrm{wt} / \mathrm{min}$ for one hour plus intraductal sterile saline $(1000-2000 \mathrm{ml})$. During the infusion an online mono-

Table 1 Demographic and clinical characteristics of patients

\begin{tabular}{|c|c|c|c|c|c|c|c|}
\hline $\begin{array}{l}\text { Case } \\
\text { no }\end{array}$ & $\begin{array}{l}\text { Age } \\
(y r)\end{array}$ & Sex & $\begin{array}{l}\text { CBD stones } \\
\text { before } \\
\text { treatment } \\
\text { (n) }\end{array}$ & $\begin{array}{l}\text { Size of gall } \\
\text { stones }\end{array}$ & Intraductal treatment & Subsequent treatments & $\begin{array}{l}\text { Outcome of } \\
\text { the treatment }\end{array}$ \\
\hline 1 & 68 & $\mathbf{M}$ & 3 & $1.0-1.5 \mathrm{~cm}$ & MTBE (11 $\mathrm{ml}$ in 1 day) & Monooctanoin $(1100 \mathrm{ml}$ in 21 days) & Success \\
\hline 2 & 75 & $\mathbf{F}$ & 6 & $1 \cdot 0-1.5 \mathrm{~cm}$ & MTBE (22 $\mathrm{ml}$ in 2 days) & Monooctanoin ( $1500 \mathrm{ml}$ in 29 days) & Success \\
\hline 3 & 63 & $\mathbf{F}$ & 1 & $0.6 \mathrm{~cm}$ & Saline ( $1000 \mathrm{ml}$ in 1 day) & None & Success \\
\hline 5 & 58 & $\mathbf{M}$ & 1 & $1 \cdot 2 \mathrm{~cm}$ & Saline $(1300 \mathrm{ml}$ in 1 day $)$ & None & Success \\
\hline 6 & 57 & $\mathbf{F}$ & 1 & $0.8 \mathrm{~cm}$ & Monooctanoin (1050 $\mathrm{ml}$ in 13 days) & None & Success \\
\hline 7 & 57 & $\mathbf{M}$ & 1 & $0.7 \mathrm{~cm}$ & Monooctanoin (1030 $\mathrm{ml}$ in 16 days) & None & Success \\
\hline 8 & 62 & $\mathbf{F}$ & 1 & $0.6 \mathrm{~cm}$ & Monooctanoin ( $850 \mathrm{ml}$ in 11 days) & None & Success \\
\hline
\end{tabular}


Table 2 Comparison of serum liver function tests before and after treatment in rabbits

\begin{tabular}{|c|c|c|c|c|c|c|c|c|}
\hline & \multirow{2}{*}{$\begin{array}{l}\text { AST }(\mu k a t / l) \\
\text { Before }\end{array}$} & \multirow[b]{2}{*}{ After } & \multirow{2}{*}{$\begin{array}{l}\text { ALT ( } \mu k a t / l) \\
\text { Before }\end{array}$} & \multirow[b]{2}{*}{ After } & \multirow{2}{*}{$\begin{array}{l}\text { AP }(\mu k a t / l) \\
\text { Before }\end{array}$} & \multirow[b]{2}{*}{ After } & \multicolumn{2}{|c|}{ Total bilirubin $(\mu \mathrm{mol} / \mathrm{l})$} \\
\hline & & & & & & & Before & After \\
\hline MTBE & $1.02(0 \cdot 18)$ & $3.85(2.03)^{*}$ & $0.93(0.11)$ & $2.53(0.68)^{*}$ & $0.31(0.08)$ & $2 \cdot 00(1 \cdot 28)^{*}$ & $3.0(0 \cdot 7)$ & $4.9(2.0)$ \\
\hline Control & $0.92(0.10)$ & $0.93(0.15)$ & $0.90(0.16)$ & $0.85(0.11)$ & $0.36(0 \cdot 10)$ & $0.25(0.10)$ & $2.9(0.5)$ & $3.4(0.7)$ \\
\hline
\end{tabular}

${ }^{*} \mathrm{p}<0.05 v$ pretreatment value and corresponding value of control group. Results are expressed as the mean (SD) of four animals for each group.

meter was broken off at the $30 \mathrm{~cm}$ mark to prevent excessive pressure in the biliary tree. In one case the flushing treatment was repeated allowing an interval of 24 hours between one treatment and the other. Monooctanoin (Capmul 8210, Stokely Van Camp $\mathrm{Co}$, Indianapolis, Indiana) was infused continuously through the indwelling biliary drainage at a rate of 3-4 $\mathrm{ml} / \mathrm{h}$ by a precision pump. An online monometer was used to constantly monitor biliary pressure: monooctanoin infusion was interrupted if pressure in the biliary system exceeded $20 \mathrm{~cm}$. No other procedures, such as endoscopic sphincterotomy, were attempted in all these patients.
STATISTICAL ANALYSIS

The quantitative variables have been analysed by split-plot analysis of variance and Tukey's multiple comparison test. ${ }^{15}$ The results have been reported as mean (SD).

\section{Results}

All the animals remained alive for the entire experimental period. During intraductal MTBE instillation, transient vomiting, dyspnoea and somnolence occurred, and the characteristic odour of the compound was detected on the breath of the animals.

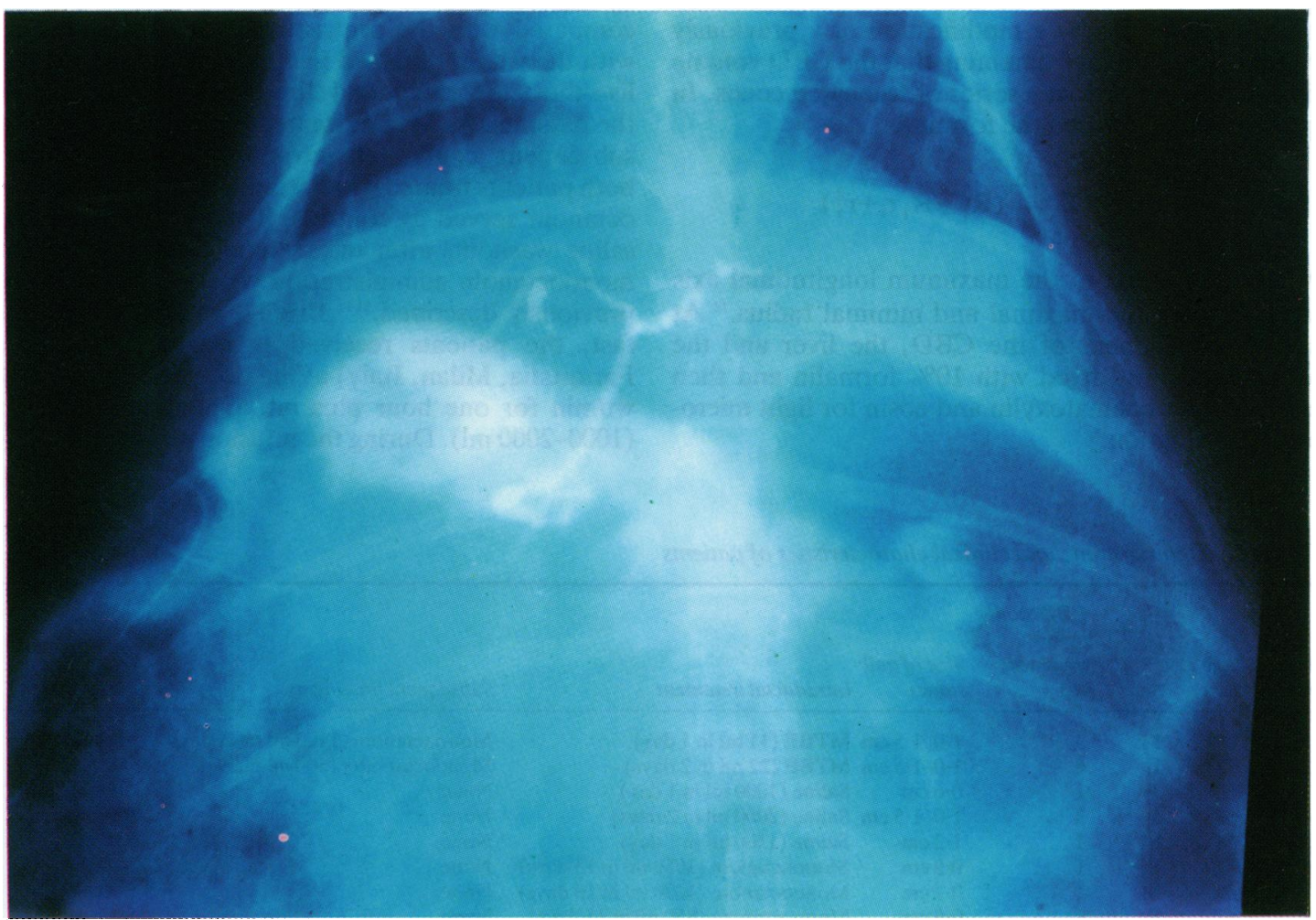

Fig. 1 Cholangiogram from one rabbit before intraductal treatment. 


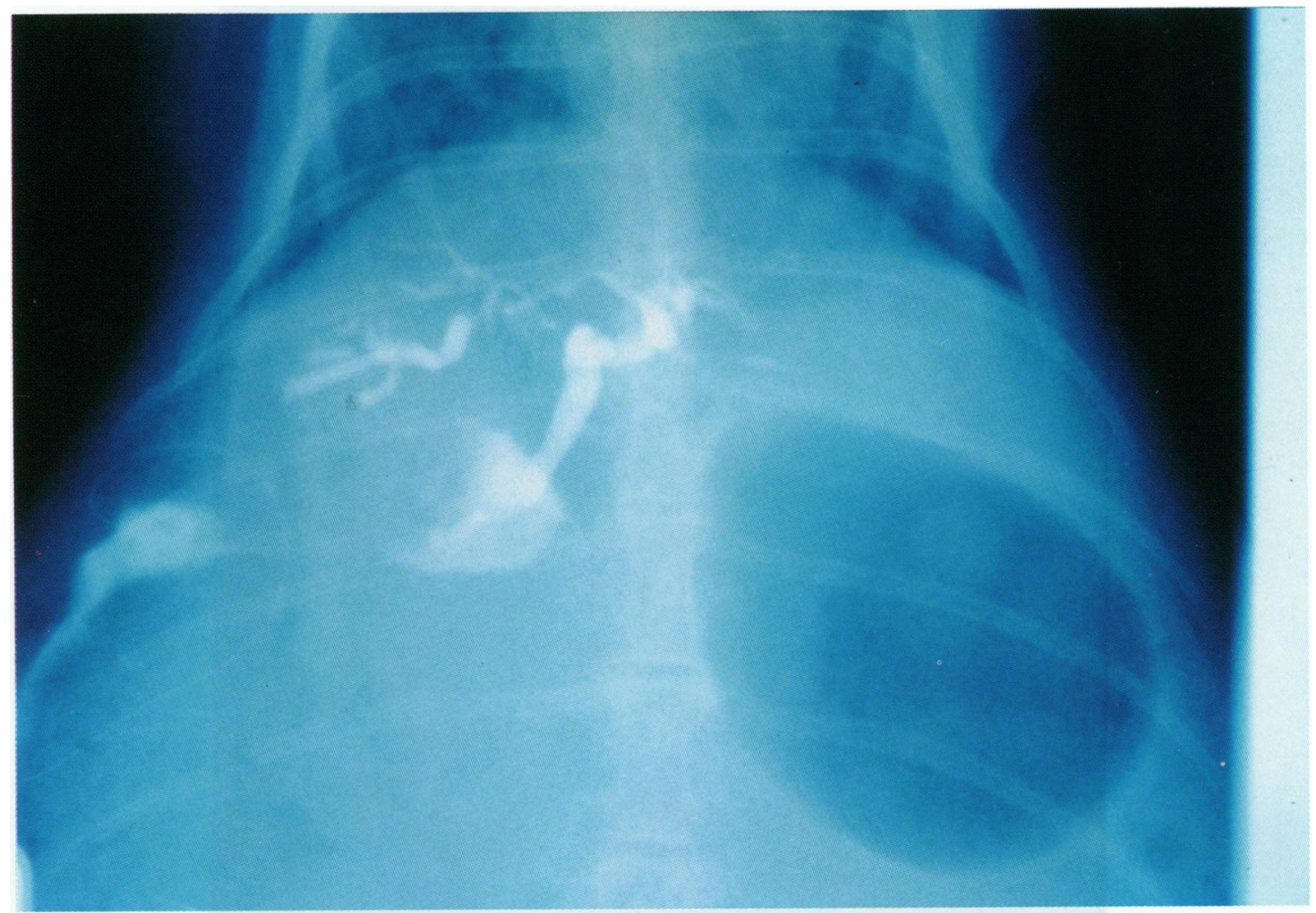

Fig. 2 Cholangiogram from the same rabbit of Figure 1 one week after intraductal MTBE administration (1 ml/kg body wt daily for two days). The CBD appears dilated.

Rabbits given MTBE showed significant deviations in serum alanine aminotransferase (ALT), aspartate aminotransferase (AST) and alkaline phosphatase (AP) from the controls (Table 2). Bile cultures gave negative results in all the cases. The cholangiographies carried out in basal conditions and one week after the last intraductal infusion revealed a marked increase of the post-treatment CBD size in MTBE $v$ control rabbits (Figs 1 and 2). Accordingly, the posttreatment CBD volume was significantly greater in MTBE treated rabbits than in controls (Table 3). In two additional rabbits, a cholangiographic test was carried out at the end of the intraductal MTBE infusion. No spasm of the sphincter of Oddi was detected. At autopsy on gross inspection, dilatation of the biliary tree was also detected. On light microscopy evidence of chemical cholangitis and mild duodenitis was found.

The follow up of all the patients who had received intraductal treatment one year before showed no abnormalities of blood hepatic and pancreatic function tests. In all the cases was a dilated CBD cholangiographically documented before intra- ductal treatment. Only the two MTBE treated subjects exhibited an unchanged dilatation of the CBD one year later (Figs 3 and 4).

Table 4 reports the volume of the CBD before and after the intraductal treatment. Subjects treated with saline or monooctanoin had a marked decrease of the CBD volume in respect to baseline value. On the other hand, the two patients given MTBE exhibited no appreciable change in CBD volume one year later.

Table 3 Comparison of the CBD volume before and after treatment in rabbits

\begin{tabular}{lll}
\hline & \multicolumn{1}{l}{$C D B(\mathrm{ml})$} & \\
\cline { 2 - 3 } & Before & After \\
\hline MTBE & $0.044(0.010)$ & $0.214(0.024)^{*}$ \\
Control & $0.042(0.012)$ & $0.046(0.008)$ \\
\hline
\end{tabular}

${ }^{*} \mathrm{p}<0.01 v$ pretreatment value and corresponding value of control group. Results are expressed as the mean (SD) of four animals for each group. 


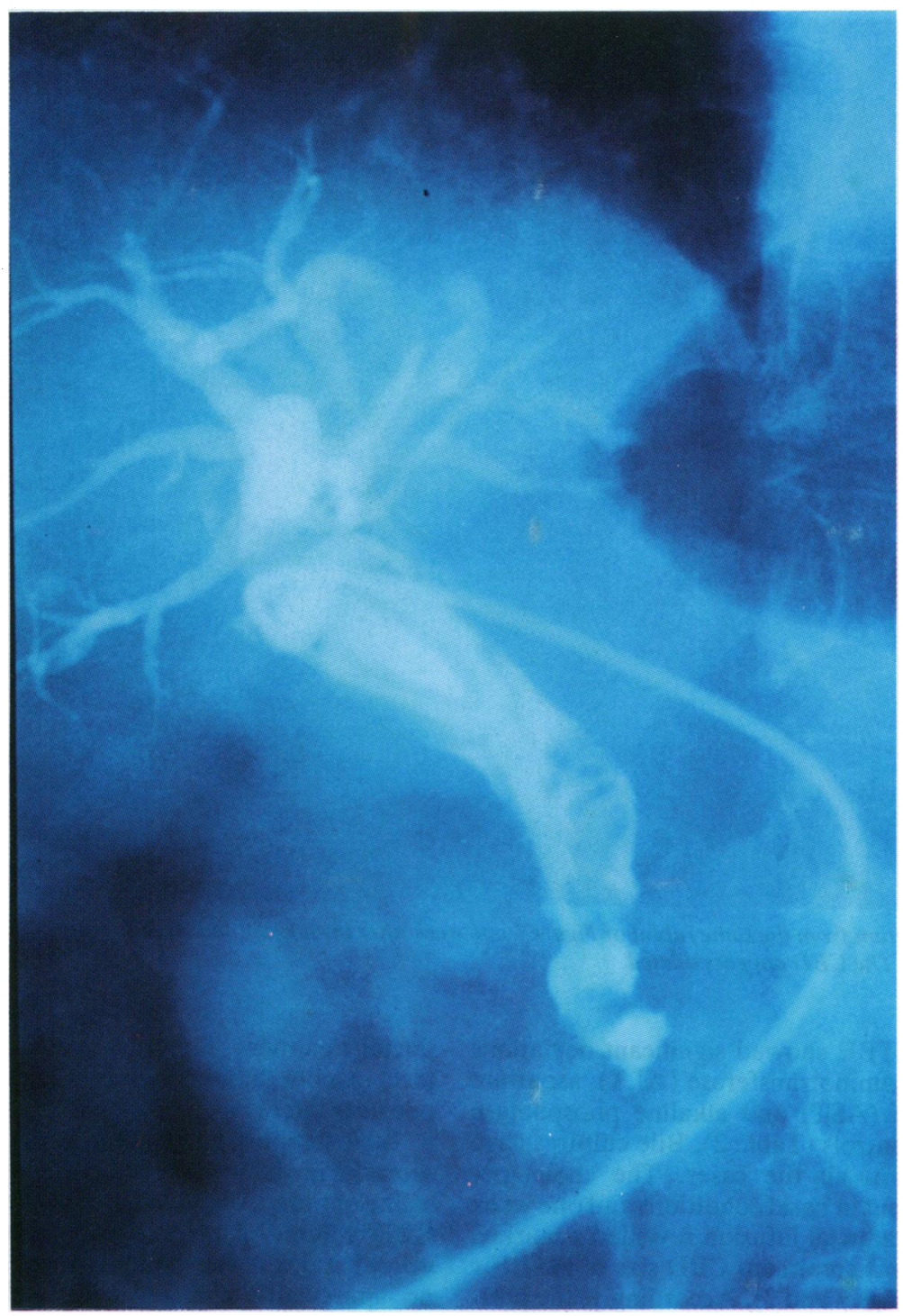

Fig. 3 Transbiliary catheter cholangiogram showing multiple radiolucent stones filling a dilated CBD in one patient before intraductal MTBE.

\section{Discussion}

The experiments indicated that the direct infusion of moderate amounts of MTBE into the CBD produces biochemical and histological evidence of cholangitis in rabbits. These findings add to the previous data by Allen et $\mathrm{al}^{1}$ who described some adverse effects in dogs treated with MTBE instilled into the gall bladder. In particular, they referred to an increase in serum alkaline phosphatase, inflammatory changes in gall bladder specimens as well as mild duodenitis in some animals. They also reported strong analogies between MTBE and diethyl ether, which is known to exert irritating effects on skin and mucous membranes. In our experimental conditions the toxicity of MTBE appeared more striking as we also noted a significant increase in serum ALT and AST: the discrepancy may be related to the modalities of MTBE administration as well as to the different susceptibility of the animal species. In this regard, it 


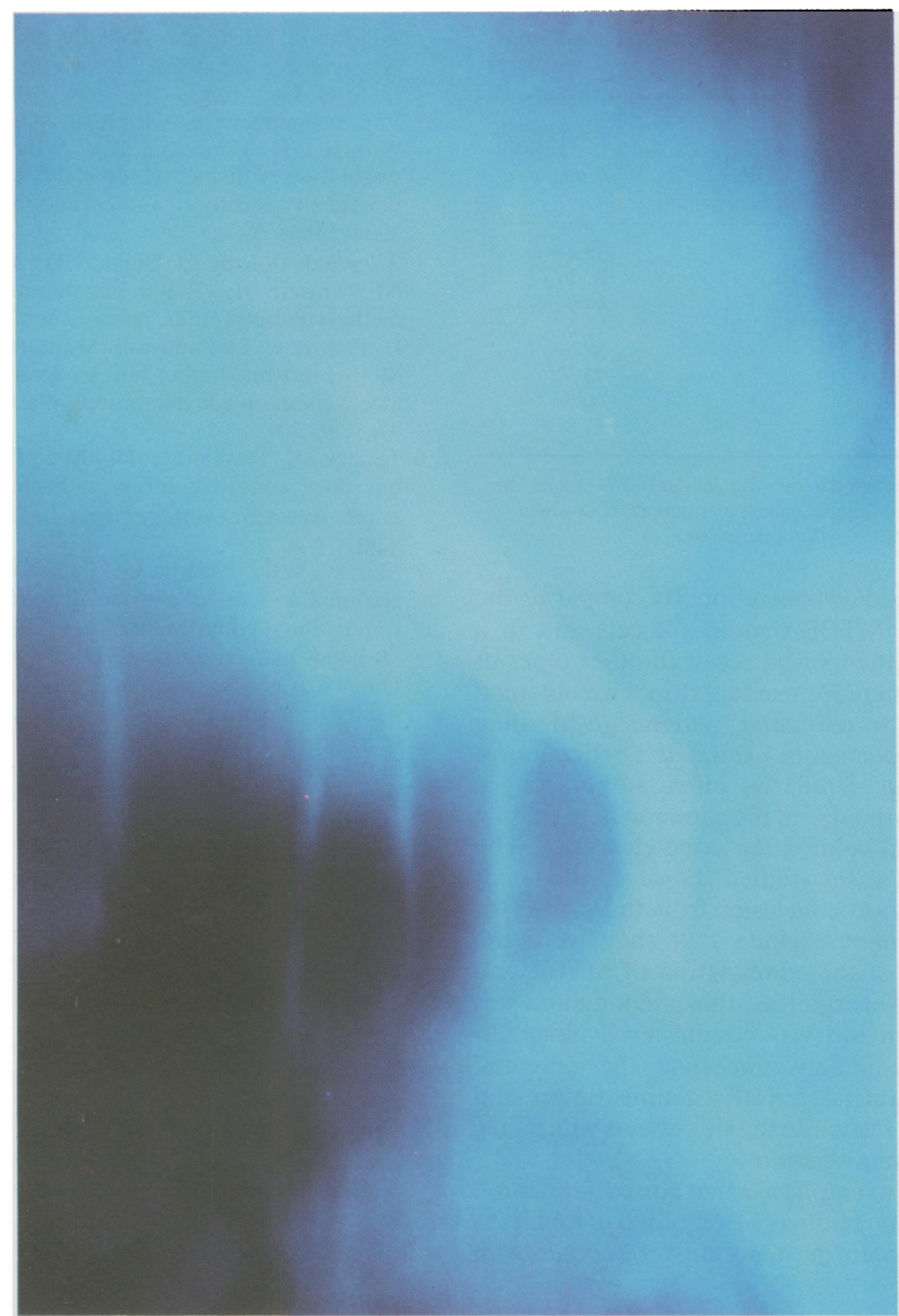

Fig. 4 Intravenous cholangiogram from the same patient of Figure 3 one year after intraductal MTBE. The CBD shows a persistent dilatation in absence of any residual concretion.

should be noted that rabbits are very sensitive to chemical hepatotoxicity ${ }^{16}{ }^{17}$ so that we cannot exclude a lower capability of these animals to tolerate MTBE in comparison with dogs. Moreover, the findings herein reported do not necessarily apply to man. The results of this experimental study have provided another information concerning the capability of MTBE of modifying the size of the CBD. In two additional animals, the dilatation of the biliary tree was still evident three weeks after MTBE administra- tion. The mechanism whereby MTBE induces a long lasting modification of the CBD volume is still unexplained and worthwhile of future investigations. This unexpected finding encouraged us to check CBD appearance in two patients who had received repeated cycles of infusion and aspiration of MTBE for retained CBD stones. ${ }^{5}$ This technique was used to avoid the loss of MTBE into duodenum and to prevent systemic absorption. Both patients exhibited persistent dilatation of the CBD one year later in 
Table 4 Comparison of the CBD volume before and one year after treatment in eight subjects

\begin{tabular}{|c|c|c|c|c|}
\hline $\begin{array}{l}\text { Case } \\
\text { no }\end{array}$ & $\begin{array}{l}\text { Intraductal } \\
\text { treatment }\end{array}$ & $\begin{array}{l}\text { CBD volume } \\
\text { before } \\
\text { treatment }(\mathrm{ml})\end{array}$ & $\begin{array}{l}\text { CBD volume } \\
\text { after } \\
\text { treatment }(\mathrm{ml})\end{array}$ & $\begin{array}{l}\text { CBD volume } \\
\text { (\% change v } \\
\text { pre-treatment } \\
\text { value) }\end{array}$ \\
\hline 1 & MTBE* & $5 \cdot 1$ & $6 \cdot 1$ & $+19 \cdot 6$ \\
\hline 2 & MTBE* & $12 \cdot 3$ & 8.9 & $-27 \cdot 7$ \\
\hline 3 & Saline & $5 \cdot 0$ & 0.7 & $-86 \cdot 0$ \\
\hline 4 & Saline & $11 \cdot 7$ & $1 \cdot 0$ & $-91 \cdot 5$ \\
\hline 5 & Saline & $9 \cdot 3$ & $1 \cdot 1$ & $-88 \cdot 2$ \\
\hline 6 & Monooctanoin & 11.8 & 2.9 & $-75 \cdot 5$ \\
\hline 7 & Monooctanoin & $9 \cdot 3$ & $3 \cdot 7$ & $-60 \cdot 3$ \\
\hline 8 & Monooctanoin & 8.5 & $2 \cdot 4$ & $-71 \cdot 8$ \\
\hline
\end{tabular}

*As intraductal MTBE failed to dissolve residual CBD stones, the patient underwent a subsequent course of monooctanoin which induced the disappearance of the concretions.

absence of any residual concretion. By comparing the CBD volume in MTBE-treated subjects and in a small group of patients who received other types of intraductal treatment for residual stones we obtained different results. In particular, patients given saline washout or monooctanoin exhibited a reduction of the CBD volume. Similarly, other authors ${ }^{18}$ have documented that the size of the common hepatic duct returns to normal value after stone clearance. The small number of cases studied, however, does not permit us to draw any conclusion from these observations, as we cannot exclude that they were the fortuitous result of the combination of MTBE and monooctanoin. Nevertheless, this phenomenon was not evident when Mo was administered alone. In conclusion, our findings underline the potential toxicity of intraductal MTBE administration and alert clinicians to recognise the side effects which may occur after its administration.

Again we wish to emphasise that any extrapolation of the experimental findings we obtained in rabbits to events which occur in man must be done with caution.

This study was supported by Research Grants 86:8601976.56 and 87:00480.56.115.08320 from CNR, Rome (Italy) and Research Grant 85:1201A0 from MPI, Rome (Italy). This investigation was presented in part at the 22nd Meeting of the European Association for the Study of the Liver, Turin (Italy), 3-5 September, 1987 and published in abstract form in J Hepatol 1987; 5: S67.

\section{References}

1 Allen MJ, Borody TJ, Bugliosi TF, May GR, La Russo NF, Thistle JL. Cholelitholysis using methyl tertiary butyl ether. Gastroenterology 1985; 88: 122-5.

2 Allen MJ, Borody TJ, Thistle JL. In vitro dissolution of cholesterol gallstones. A study of factors influencing rate and a comparison of solvents. Gastroenterology 1985; 89: 1097-103.

3 Van Sonnenberg E, Hofmann AF, Neoptolemus J, Wittich GR, Princethal RA, Wilson SW. Gallstone dissolution with methyl-tert-butyl ether via percutaneous cholecystostomy: success and caveats. Am J Radiol 1986; 146: 865-7.

4 Allen MJ, Borody TJ, Bugliosi TF, May GR, La Russo NF, Thystle JL. Rapid dissolution of gallstones by methyl tert-butyl ether. $N$ Engl J Med $1985 ; 312: 217-20$.

5 Di Padova C, Di Padova F, Montorsi W, Tritapepe R. Methyl tert-butyl ether fails to dissolve retained radiolucent common bile duct stones. Gastroenterology 1986; 91: 1296-300.

6 Teplick SK, Haskin PH, Goldstein RC, et al. Common bile duct stone dissolution with methyl tertiary butyl ether: experience with three patients. Am J Radiol 1987; 148: $372-4$.

7 Murray WR, Laferla G, Fullarton GM. Choledocholithiasis - in vivo stone dissolution using methyl tertiary butyl ether (MTBE). Gut 1988; 29: 143-5.

8 Di Padova C, Tritapepe R, Di Padova F, Rovagnati P, Dioguardi N. Acute ethanol administration increases biliary concentrations of total and unconjugated bilirubin in rabbits. Dig Dis Sci 1981; 26: 1095-9.

9 Holdeman LV, Moore WEC. Anaerobe laboratory manual. Blacksburg, VA: Virginia Polytechnic Institute and State University, 1972.

10 Rosseland AR, Kolmannskog F. Cholangiography in rabbits before and after papillotomy. Scand J Gastroenterol 1983; 18: 1077-82.

11 Everson GT, Braverman DZ, Johnson ML, Kern F. A critical evaluation of real-time ultrasonography for the study of gallbladder volume and contraction. Gastroenterology 1980; 79: 40-6.

12 Leutner C. Introduction to statistics, statistical tables, mathematical formulae. In: Geigy scientific tables. Basle: Ciba-Geigy Ltd, 1982: 179.

13 Tritapepe R, Di Padova C, Pozzoli M, Rovagnati P, Montorsi $\mathrm{W}$. The treatment of retained biliary stones with monooctanoin: report of 16 patients. Am J Gastroenterol 1984; 79: 710-4.

14 Tritapepe R, Di Padova C, Di Padova F. Non-invasive treatment for retained common bile duct stones in patients with $T$ tube in situ: saline washout after intravenous ceruletide. Br J Surg 1988; 75: 144-6.

15 Kirk RE. Experimental design: procedure for the behavioral sciences. Belmont, California: Books-Cole Publishing Co, 1982.

16 Miyai K, Javitt NB, Gochman N, Jones HM, Baker D. Hepatotoxicity of bile acids in rabbits. Ursodeoxycholic acid is less toxic than chenodeoxycholic acid. Lab Invest 1982; 46: 428-37.

17 Cohen BI, Hofmann AF, Mosbach EH, et al. Differing effects of nor-ursodeoxycholic or ursodeoxycholic acid on hepatic histology and bile acid metabolism in the rabbit. Gastroenterology 1986; 91: 189-97.

18 Graham MF, Cooperberg PL, Cohen MM, Burhenne HJ. The size of the normal common hepatic duct following cholecystectomy: an ultrasonographic study. Radiology 1980; 135: 137-9. 